\title{
Adherence to osteoporosis regimens among men and analysis of risk factors of poor compliance: a 2-year analytical review
}

\author{
Chun-Kai Chiu ${ }^{1 \dagger}$, Ming-Chun Kuo ${ }^{2 \dagger}$, Shan-Fu Yu ${ }^{3{ }^{*}}$, Ben Yu-Jih Su ${ }^{3}$ and Tien-Tsai Cheng ${ }^{3^{*}+}$
}

\begin{abstract}
Background: To investigate adherence and patient-specific factors associated with poor compliance with osteoporosis regimens among men.

Methods: In this retrospective chart review study, we collected data on male patients with osteoporosis treated in accordance with therapeutic recommendations. Adherence was determined by the compliance and persistence of those patients who had been dispensed an osteoporosis regimen after an index prescription. All osteoporosis regimens were considered equivalent for the purpose of investigating adherence.

Results: The prescriptions of 333 males met the inclusion criteria for data collection. The mean age was $68.6 \pm$ 10.4 years. The median medication possession ratio (MPR, \%) at years 1 and 2 was $90.1 \%$ (interquartile range (IQR) 19-100) and 53.7\% (IQR 10.4-100), respectively; 52.3\% of male patients at year 1 and $37.5 \%$ at year 2 had good compliance (defined as a MPR $\geqq 80 \%$ ). The 1- and 2-year persistence rates were $45.9 \%$ and $30.0 \%$, respectively. Patient-specific factors associated with poor compliance (MPR $<80 \%)$ during year 1 were first prescriptions given by orthopedists (odds ratio $(\mathrm{OR})=2.67 ; 95 \%$ confidence interval $(\mathrm{Cl})=1.58-4.53$; adjusted $\mathrm{OR}=2.30,95 \% \mathrm{Cl}=1.26-4.22$, $\mathrm{p}=0.007)$. Male patients with rheumatoid arthritis (RA) $(\mathrm{OR}=0.22,95 \% \mathrm{Cl}=0.06-0.78$, adjusted $\mathrm{OR}=0.19,95 \% \mathrm{Cl}=$ 0.04-0.81, $\mathrm{p}=0.025)$ and baseline bone mineral density $(\mathrm{BMD})$ measurements $(\mathrm{OR}=0.52,95 \% \mathrm{Cl}=0.32-0.85$; adjusted $\mathrm{OR}=0.51 ; 95 \% \mathrm{Cl}=0.28-0.93, \mathrm{p}=0.029)$ were less likely to have poor compliance.

Conclusions: Adherence to osteoporosis regimens in males was suboptimal in our study. Poor compliance was more likely in prescription of the first anti-osteoporotic regimen by an orthopedist. Men with RA and BMD measurements before therapy had a lower risk of non-adherence. Healthcare professionals need to target patients with specific factors to improve adherence to osteoporotic regimens.
\end{abstract}

Keywords: Adherence, Osteoporosis regimens, Compliance, Persistence

\section{Background}

The prevalence of osteoporosis and osteoporotic fractures has increased worldwide during the past few decades [1]. Osteoporosis and related fractures are a common cause of morbidity and mortality in the elderly globally [2-4]. There are significant differences in skeletal size and structure between men and women that

\footnotetext{
* Correspondence: yu.shanfu@msa.hinet.net; tiantsai@ms2.hinet.net ${ }^{\dagger}$ Equal contributors

${ }^{3}$ Division of Rheumatology, Allergy and Immunology, Department of Internal Medicine, Kaohsiung Chang Gung Memorial Hospital and Chang Gung University College of Medicine, No 123, Ta-Pei Road, Niaosung, Kaohsiung 833, Taiwan

Full list of author information is available at the end of the article
}

account for differences in fracture incidence, location and outcomes [5]. While women sought medical attention for the prevention of bone loss, men were referred because of the presence of signs and symptoms indicating a more severe disease [6]. In Taiwan, the prevalence of osteoporosis between 1999 and 2001 among subjects aged 50 years or older was $1.63 \%$ for men and $11.35 \%$ for women [7]. Although the prevalence of osteoporosis is lower in men than in postmenopausal women globally, the mortality and morbidity of osteoporosis among men are higher than among women [5,8-10].

A variety of regimens including bisphosphonates, estrogen, selective estrogen receptor modulators, calcitonin,

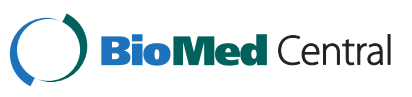


strontium ranelate, and teriparatide are currently available in Taiwan for the prevention and treatment of osteoporosis, and have demonstrated anti-fracture efficacy in postmenopausal women and in men $[11,12]$. The efficacy of osteoporosis medications depends on adherence, which consists of both compliance and persistence. Despite the availability of several treatment options for osteoporosis, adherence to anti-osteoporotic therapy in real-world practice is suboptimal and has generally been lower than in clinical trials. In a meta-analysis of 24 studies, $40-70 \%$ of osteoporotic patients were reported to be non-adherent [13]. Although male subjects at an advanced age often have osteoporosis and osteoporotic fractures, little is known about their exact adherence rates because researchers rarely include men in osteoporosis adherence studies, [14,15] or seldom report adherence rates separately or exclusively for men. Non-adherence to osteoporosis regimens is clearly associated with poorer outcomes. Therefore, it is essential to improve drug adherence for both postmenopausal women and osteoporotic men, so as to enhance therapeutic outcomes.

Claims or pharmacy databases are usually used to measure adherence and to determine factors associated with non-adherence to osteoporosis medications. Nonadherence in women has been previously reported to be related to the drugs, the patients, and the doctors [16-18]. Few studies in the literature have investigated the factors affecting adherence among males with osteoporosis $[14,15]$. Therefore, further identification of risk factors for non-adherence among males with osteoporosis may help improve adherence and ultimately reduce fracture risk. In addition, many studies have demonstrated that realizing the anti-fracture efficacy of osteoporosis medications may require several years of therapy $[19,20]$, but most reports have investigated adherence to anti-osteoporotic therapy within one year only $[13,21,22]$.

In this retrospective chart review study of male patients with osteoporosis treated at a single medical center in southern Taiwan, we aimed to investigate 1- and 2-year adherence (both compliance and persistence) to osteoporosis regimens (including bisphosphonates and calcitonin), and also explore the risk factors associated with poor adherence.

\section{Methods}

\section{Participants}

This was a retrospective medical chart review study. The charts of all consecutive male subjects (aged $>18$ years) who had been diagnosed with osteoporosis and had been dispensed osteoporosis regimens between 1 January 2001 and 31 July 2007 in Chang-Gung Memorial Hospital, Kaohsiung (CGMHK) Medical Center were retrieved. Our hospital is a tertiary care referral center located in Kaohsiung County in southern Taiwan, serving a population of about 2,000,000. The study was conducted according to the protocol approved by the Ethics Committee of Chang Gung Memorial Hospital (IRB No: 97-0165C), and a waiver was granted for obtaining informed consent.

We searched the computerized databases in CGMHK for the following diagnostic codes (International Classification of Diseases, Ninth Edition, Clinical Modification, ICD-9-CM): 733.0 (osteoporosis), 733.01 (senile osteoporosis), 733.02 (idiopathic osteoporosis), 733.03 (disuse osteoporosis), 733.00 (osteoporosis, unspecified), 733.09 (osteoporosis, others), 781.91 (loss of height), V17.81 (family history of osteoporosis), V82.81 (specific screening for osteoporosis), 8054 (spine fracture), and 82,100 (hip fracture). Target osteoporosis regimens included Miacalcic $^{\circ}$ nasal spray (code: PMF022E, calcitonin 200 iu, Novartis), Fosamax ${ }^{\circ}$ (10) (code: PMF050M, alendronate, $10 \mathrm{mg}$ tab, Merck Sharp \& Dohme), Fosamax ${ }^{\circ}$ (70) (code: PMF052M, alendronate, $70 \mathrm{mg}$ tab, Merck Sharp \& Dohme), and Forteo ${ }^{\circ}$ (code: PMF042P, teriparatide, 20 $\mathrm{mcg} / \mathrm{shot}$, Eli Lilly and Company). Risedronate was not available in Taiwan and ibandronate, zoledronic acid, and strontium ranelate were available only after 2007 in Taiwan. Therefore, the anti-osteoporotic agents targeted in this study did not include these regimens.

\section{Inclusion and exclusion criteria}

Medical records of male subjects who had been dispensed the above regimens under National Osteoporosis Foundation (NOF) treatment recommendations (2008) [23] or the American College of Rheumatology (ACR) guidelines for glucocorticoid-induced osteoporosis (GIOP) (2001) during the study period were reviewed [24]. Patients that did not fulfill the above inclusion criterion, whose chart had been destroyed, who received medications for conditions other than osteoporosis, or those that expired during the follow-up period were excluded.

\section{Data collection}

The demographic and clinical characteristics of the study subjects, including age, gender, selected comorbid conditions, baseline dual energy X-ray absorptiometry (DXA), evidence of prior osteoporotic fracture, sites of osteoporotic fracture, history of vertebroplasty, first prescriber of osteoporosis regimen, and consumption of alcohol/smoking, were examined. Age was assessed at the date of therapy initiation. Comorbidities documentation (including hypertension, cardiac diseases, chronic respiratory diseases, endocrine diseases, chronic kidney disease, hepatobiliary diseases, malignant neoplasms, neuropsychiatric disorders, and rheumatoid arthritis [RA]) and evidence of prior osteoporotic fracture 
(vertebrae, hip, and other sites of osteoporotic fracture) were ascertained on the basis of the opinion of relevant specialists.

\section{Calculation of adherence}

Adherence, as defined by Cramer et al. [25] was evaluated using the parameters of compliance and persistence. Compliance was estimated by the medication possession ratio (MPR) and persistence by the time from treatment initiation to discontinuation with no medication refill gap for a period of 30 days or more during the period of interest. Study patients were rated as having good compliance if the annual MPR $\geq 80 \%$. MPR was defined as the ratio of actually available doses against the expected doses that the patient should possess over a fixed period of time. The 1-year and 2-year MPR were defined as being the percentage of days with an available drug supply within a predefined interval of 365 days (year 1) or 730 days (year 2), respectively. Persistence rate (PR) was defined as the percentage of patients that were still on medication at a given time with no refill gap in medication-taking for a period of 30 days or more. The risk factors of poor compliance (MPR $<80 \%$ ) were evaluated at the end of year 1 . In the sub-group analysis, we excluded those subjects with MPR $<80 \%$ at the end of year 1 and the MPR of the remaining subjects (MPR $\geq 80 \%$ at year 1 ) were reevaluated at the end of year 2 . The corresponding risk factors were analyzed using the logistic regression model accordingly.

\section{Statistical methods}

Patient characteristics were reported as simple descriptive statistics (i.e., mean \pm standard deviation $[\mathrm{SD}]$ ). The median ( $25 \%$ to $75 \%$ inter-quartile range, IQR) was used to summarize data for continuous variables and percentages with a non-normal distribution. In univariate analysis, categorical variables were compared using the chi-square test or Fisher's exact test. Continuous variables were compared using the t-test. The cumulative distribution curves of persistence were generated using the Kaplan-Meier method. Multivariate analysis was performed by estimating the odds ratio (OR) and its $95 \%$ confidence interval (CI) using a logistic regression model. All variables of baseline characteristics with a $\mathrm{p}<0.05$ in univariate analysis were considered for inclusion in the multivariate model. Statistical significance was defined as a p-value of less than 0.05. All analyses were performed using the SPSS program, version 15.5 (SPSS, Chicago, IL) for Windows XP Professional.

\section{Results}

Patient characteristics

A total of 8280 charts with predefined diagnostic codes were retrieved. After excluding medical records that were not traceable, 3589 charts were reviewed. In all, 333 male subjects met the inclusion criteria for data collection. The mean age of the subjects was $68.6 \pm$ 10.4 years. Of the 333 subjects, 282 (84.7\%) fulfilled the NOF recommendation and the remaining (15.3\%) fulfilled the ACR guideline. Two thirds of the patients in our cohort had a comorbidity of interest. The most prevalent comorbidity among all patients was hypertension. Most of the patients (90.4\%) had a baseline osteoporotic fracture. Vertebral fracture was the most common $(79.6 \%)$ in our cohort, followed by hip fracture (14.4\%). DXA measurement at baseline was available in $28.2 \%$ of patients. Rheumatologists and orthopaedists were the most common (72.3 or $72.4 \%$ ) first prescribers of osteoporosis regimens. Baseline patient characteristics in this study are shown in Table 1.

\section{Drug adherence and patient-specific factors associated with poor compliance}

In terms of compliance, the median MPR at year 1 and year 2 was 90.1\% (IQR 19-100) and 53.7\% (IQR 10.4$100)$, respectively. More than half $(52.3 \%)$ of the males had good compliance (MPR $\geq 80 \%$ ) at year 1 , but only $37.5 \%$ through year 2 . In addition, the PR of all 333 men at year 1 and year 2 was $45.9 \%$ and $30.0 \%$, respectively. One-year compliance was lower with start prescriptions by orthopedists $(\mathrm{OR}=2.673, \mathrm{p}=0.000$; CI, 1.58-4.53; adjusted $\mathrm{OR}=2.302, \mathrm{CI}, 1.26-4.22, \mathrm{p}=0.007$, compared to start prescriptions by rheumatologists). Male patients with RA (OR $=0.22,95 \% \mathrm{CI}=0.06-0.78$, adjusted $\mathrm{OR}=$ $0.19,95 \% \mathrm{CI}=0.04-0.81, \mathrm{p}=0.025)$ and baseline bone mineral density (BMD) measurements $(\mathrm{OR}=0.52,95 \%$ $\mathrm{CI}=0.32-0.85$; adjusted $\mathrm{OR}=0.51 ; 95 \% \mathrm{CI}=0.28-0.93$, $\mathrm{p}=0.029)$ were less likely to have poor compliance (Table 2). There was no association between the other baseline characteristics and poor compliance at year 1 .

In addition, we also analyzed the subgroup with a MPR $\geq 80 \%$ at year 1 to recognize the predictors of nonadherence at year 2. Baseline patient characteristics in the subgroup $(\mathrm{n}=174)$ are shown in Table 1 . No identified factor was associated with poor compliance during year 2 in this subgroup of subjects (Table 2).

\section{Discussion}

Osteoporosis in men has been documented as a serious health issue recently, as osteoporosis can cause higher morbidity and mortality in men than in women, though it affects males less frequently $[5,10]$. Indeed, whereas numerous data related to the adherence of female osteoporosis patients are available, data are scarce for men. To our knowledge, the present study is one of few that have investigated the factors affecting medication compliance among males with osteoporosis. The findings were in accord with the results of our total cohort [26], 
Table 1 Characteristics of the study subjects

\begin{tabular}{|c|c|c|}
\hline Characteristic & Total cohort & Subgroup* \\
\hline Number of subjects (male) & 333 & 174 \\
\hline Age $(y)$, mean $\pm S D$ & $68.6 \pm 10.4$ & $67.1 \pm 10.9$ \\
\hline Comorbidity, n (\%) & $229(68.8)$ & $116(66.7)$ \\
\hline \multicolumn{3}{|l|}{ Comorbid diseases, n (\%) } \\
\hline 1. Hypertension & $110(33.0)$ & $61(35.1)$ \\
\hline 2. Neuropsychiatric & $58(17.4)$ & $28(16.1)$ \\
\hline 3. Cardiac & $52(15.6)$ & $20(11.5)$ \\
\hline 4. Endocrine/metabolic & $51(15.3)$ & $22(12.6)$ \\
\hline 5. Respiratory & $35(10.5)$ & $16(9.2)$ \\
\hline 6. Malignancy & $23(6.9)$ & $12(6.9)$ \\
\hline 7. Chronic kidney disease & $22(6.6)$ & $10(5.7)$ \\
\hline 8. Hepatobiliary & $21(6.3)$ & $15(8.6)$ \\
\hline 9. Rheumatoid arthritis & $17(5.1)$ & $14(8.0)$ \\
\hline Fracture history, n (\%) & $301(90.4)$ & $151(86.8)$ \\
\hline \multicolumn{3}{|l|}{ Fracture sites, n (\%) } \\
\hline Spine & $265(79.6)$ & $134(77.0)$ \\
\hline Hip & $48(14.4)$ & $21(12.1)$ \\
\hline Others ${ }^{@}$ & $21(6.3)$ & $8(4.6)$ \\
\hline Baseline DXA, n (\%) & $94(28.2)$ & $60(34.5)$ \\
\hline \multicolumn{3}{|l|}{ BMD T-score (SD), mean \pm SEM } \\
\hline Spine & $-2.0 \pm 0.2$ & $-1.9 \pm 0.2$ \\
\hline Femoral neck & $-2.1 \pm 0.1$ & $-1.9 \pm 0.1$ \\
\hline Total hip & $-1.7 \pm 0.1$ & $-1.6 \pm 0.2$ \\
\hline \multicolumn{3}{|l|}{ First prescriber, n (\%) } \\
\hline Rheumatology & $140(42.0)$ & $85(48.9)$ \\
\hline Orthopedics & $101(30.3)$ & $37(21.3)$ \\
\hline Others $^{\#}$ & $92(27.6)$ & $52(29.9)$ \\
\hline \multicolumn{3}{|l|}{ Enrolment criteria } \\
\hline NOF recommendation, n (\%) & $282(84.7)$ & $144(82.8)$ \\
\hline ACR guideline, $n(\%)$ & $51(15.3)$ & $30(17.2)$ \\
\hline Vertebroplasty, n (\%) & $11(3.3)$ & $6(3.4)$ \\
\hline Tobacco use & $1(0.3)$ & $0(0)$ \\
\hline Alcohol use & $2(0.6)$ & $1(0.6)$ \\
\hline
\end{tabular}

*Subjects with MPR $\geq 80 \%$ at year 1; NOF (2008): Clinician's Guide to Prevention and Treatment of Osteoporosis by the National Osteoporosis Foundation (2008); ACR (2001): Recommendations for the treatment and prevention of glucocorticoid-induced osteoporosis by the American College of Rheumatology (2001); DXA: Dual energy X-ray absorptiometry; BMD: bone mineral density; SD: standard deviation; SEM: standard error of the mean; Serum creatinine $>1.4 \mathrm{mg} / \mathrm{dl} ;{ }^{\circledR}$ : including rib, wrist, upper arm and pelvis; \#: Physician of Family Medicine, Metabolism, Rehabilitation.

of which more than $90 \%$ of subjects were female: adherence among male subjects was suboptimal. In contrast with previous investigations of female osteoporosis, our survey revealed the major risk factors of poor compliance at year 1 were index prescription by orthopedists and not having undergone baseline BMD measurement before pharmacologic treatment for osteoporosis was initiated. However, male subjects with RA were more likely to have good compliance.

Compliance with medications used to treat or prevent osteoporosis ranged from $34 \%$ to $94.6 \%$ at 1 year [27-31] and $27 \%$ to $43 \%$ at 2 years $[27,32]$. However, the results were subject to various definitions of compliance, and female gender, bisphosphonate users and different study populations were mainly focused on in each investigation $[28,30]$. Our data examined adherence not only among male users of oral (daily and weekly) bisphosphonates, but also among male users of calcitonin. Hansen et al. [14] reported that adherence to alendronate in male veterans during the first 12 and 24 months of therapy was $59 \%$ and $54 \%$, respectively. A small series study by Cevikoi A [15] demonstrated that full compliance rates for the 1- and 3-year periods were $49.4 \%$ and $17.9 \%$, respectively. The results of our investigation of good compliance at the first year were similar to those of most studies on postmenopausal women [14,32,33]. However, at year 2, good compliance in our cohort was $37.5 \%$, which was lower than that in Hansen's study [14]. A recent study on compliance among male subjects reported that the 1-year good compliance (MPR $\geq 80 \%$ ) and persistence rates were $91 \%$ and $39.7 \%$, respectively [21]. They attributed the relatively high 1-year good compliance rate to (1) including both new and existing patients with at least 3 prescriptions; (2) the specific ethnic group (a Dutch population); and (3) reimbursement of all osteoporosis medications [21]. That was in contrast to our study population, which had fewer than 3 prescriptions and limited reimbursement for fracture subjects.

Previous investigations that were mainly focused on bisphosphonate users demonstrated 1-year PRs ranging from $24 \%$ to $74.8 \%$ [15,21,34-36]. In our study, the persistence curve revealed an obvious drop (38.3\%) in the first year, but a less prominent (19.5\%) drop in the second year among those subjects persistent with their medication at the end of the first year. This was similar to the observation in several studies on adherence to anti-osteoporosis agents among postmenopausal women [37-39]. The previous study had demonstrated that increasing age, pain, no use of diagnostic tests, and male showed a positive effect on the probability of quitting the anti-osteoporotic medication [40]. It also suggests that improving adherence in the first year is essential to achieving a better therapeutic response for either gender. Therefore, the factors related to inadequate compliance for each year were investigated in the current study.

Possible factors affecting medication adherence have been reviewed in the literature and include side effects, smoking behavior, surveying for bone density during therapy, educational status, social support, marital status, and income $[14,15,41]$. However, these factors were 
Table 2 Factors associated with poor-compliance in subjects of total cohort and subgroup

\begin{tabular}{|c|c|c|c|c|c|c|c|c|c|c|}
\hline \multirow{3}{*}{ Risk factors } & \multicolumn{5}{|c|}{ Total subjects at year $1(n=333)$} & \multicolumn{5}{|c|}{ Subgroup subjects at year $2(n=174)^{a}$} \\
\hline & \multirow[t]{2}{*}{ n (\%) } & \multicolumn{2}{|c|}{ Univariate analysis } & \multicolumn{2}{|c|}{ Multivariate analysis } & \multirow[t]{2}{*}{ n (\%) } & \multicolumn{2}{|c|}{ Univariate analysis } & \multicolumn{2}{|c|}{ Multivariate analysis } \\
\hline & & OR $95 \% \mathrm{Cl}$ & p-value & OR $95 \% \mathrm{Cl}$ & p-value & & OR 95\% Cl & p-value & OR 95\% Cl & p-value \\
\hline Age & & $1.03(1.01-1.05)$ & 0.007 & $1.02(0.99-1.05)$ & 0.132 & & $0.97(0.94-0.99)$ & 0.045 & $0.97(0.94-1.01)$ & 0.100 \\
\hline \multicolumn{11}{|l|}{ First prescribed by } \\
\hline Rheumatologist & $55(34.6)$ & 1.0 (referent) & & 1.0 (referent) & & $24(48.0)$ & 1.0 (referent) & & 1.0 (referent) & \\
\hline Orthopedist & $64(40.3)$ & $2.67(1.58-4.53)$ & 0.000 & $2.30(1.26-4.22)$ & 0.007 & $13(26.0)$ & $1.38(0.60-3.14)$ & 0.447 & $1.52(0.58-3.96)$ & 0.394 \\
\hline Others & $40(25.2)$ & $1.19(0.70-2.03)$ & 0.525 & $1.12(0.62-2.05)$ & 0.709 & $13(26.0)$ & $0.85(0.39-1.86)$ & 0.679 & $0.86(0.35-2.14)$ & 0.746 \\
\hline DXA & $13(8.2)$ & $0.52(0.32-0.85)$ & 0.008 & $0.51(0.28-0.93)$ & 0.029 & $17(34.0)$ & $0.97(0.49-1.94)$ & 0.932 & $0.94(0.39-2.26)$ & 0.895 \\
\hline Vertebroplasty & $5(3.1)$ & $0.91(0.27-3.04)$ & 0.877 & $0.59(0.15-2.30)$ & 0.450 & $1(2.0)$ & $0.49(0.06-4.27)$ & 0.515 & $0.71(0.07-7.08)$ & 0.769 \\
\hline \multicolumn{11}{|l|}{ Fracture site } \\
\hline Spine fracture & $131(82.4)$ & $1.40(0.81-2.40)$ & 0.225 & $1.54(0.45-5.29)$ & 0.489 & $36(72.0)$ & $0.68(0.32-1.45)$ & 0.320 & $0.37(0.05-2.95)$ & 0.345 \\
\hline Hip fracture & $27(17.0)$ & $1.49(0.81-2.76)$ & 0.204 & $1.21(0.41-3.54)$ & 0.731 & $7(14.0)$ & $1.28(0.48-3.36)$ & 0.620 & $0.47(0.06-3.50)$ & 0.457 \\
\hline Others fracture & $13(8.2)$ & $1.85(0.75-4.58)$ & 0.185 & $1.88(0.69-5.10)$ & 0.216 & $3(6.0)$ & $1.52(0.35-6.61)$ & 0.577 & $1.16(0.22-6.23)$ & 0.863 \\
\hline Tobacco use $\mathrm{e}^{\mathrm{b}}$ & $1(0.6)$ & - & 0.477 & $0.00(0.00)$ & 1.000 & $0(0)$ & - & - & - & - \\
\hline Alcohol use & $1(0.6)$ & $1.10(0.07-17.65)$ & 0.949 & $0.00(0.00)$ & 1.000 & $1(2.0)$ & $4.09(0.00)$ & 1.000 & $1.37(0.00)$ & 1.000 \\
\hline Malignancy & $11(6.9)$ & $1.00(0.43-2.34)$ & 0.994 & $0.98(0.39-2.45)$ & 0.960 & $3(6.0)$ & $0.82(0.21-3.15)$ & 0.767 & $0.78(0.19-3.27)$ & 0.734 \\
\hline Cardiac disease & $32(20.1)$ & $1.94(1.06-3.56)$ & 0.032 & $1.87(0.93-3.75)$ & 0.079 & $7(14.0)$ & $1.39(0.52-3.72)$ & 0.512 & $1.79(0.58-5.49)$ & 0.311 \\
\hline Respiratory disease & $19(11.9)$ & $1.34(0.66-2.71)$ & 0.413 & $1.22(0.57-2.63)$ & 0.610 & $4(8.0)$ & $0.81(0.25-2.65)$ & 0.729 & $0.72(0.20-2.56)$ & 0.611 \\
\hline $\begin{array}{l}\text { Neuropsychiatric } \\
\text { disease }\end{array}$ & $30(18.9)$ & $1.21(0.69-2.14)$ & 0.505 & $0.89(0.47-1.70)$ & 0.732 & $6(12.0)$ & $0.63(0.24-1.67)$ & 0.354 & $0.68(0.23-2.02)$ & 0.485 \\
\hline $\begin{array}{l}\text { Chronic kidney } \\
\text { disease }\end{array}$ & $12(7.5)$ & $1.34(0.56-3.19)$ & 0.509 & $1.35(0.51-3.58)$ & 0.548 & $2(4.0)$ & $0.60(0.12-2.95)$ & 0.533 & $0.66(0.12-3.62)$ & 0.636 \\
\hline Endocrine/metabolic & $29(18.2)$ & $1.54(0.85-2.81)$ & 0.157 & $1.81(0.90-3.64)$ & 0.095 & $6(12.0)$ & $0.92(0.34-2.51)$ & 0.871 & $0.82(0.26-2.60)$ & 0.734 \\
\hline Hypertension & $49(30.8)$ & $0.83(0.52-1.31)$ & 0.411 & $0.62(0.37-1.06)$ & 0.083 & $21(42.0)$ & $1.52(0.77-2.99)$ & 0.224 & $1.62(0.77-3.43)$ & 0.207 \\
\hline Rheumatoid arthritis & $3(1.9)$ & $0.22(0.06-0.78)$ & 0.011 & $0.19(0.04-0.81)$ & 0.025 & $4(8.0)$ & $0.99(0.30-3.32)$ & 0.989 & $0.81(0.17-3.89)$ & 0.790 \\
\hline Hepatobiliary disease & $6(3.8)$ & $0.42(0.16-1.10)$ & 0.075 & $0.44(0.16-1.25)$ & 0.124 & $2(4.0)$ & $0.36(0.08-1.64)$ & 0.185 & $0.45(0.09-2.33)$ & 0.340 \\
\hline Steroid use & $21(13.2)$ & $0.73(0.40-1.34)$ & 0.307 & $1.48(0.68-3.22)$ & 0.320 & $10(20.0)$ & $1.30(0.56-3.02)$ & 0.541 & $1.02(0.31-3.29)$ & 0.980 \\
\hline
\end{tabular}

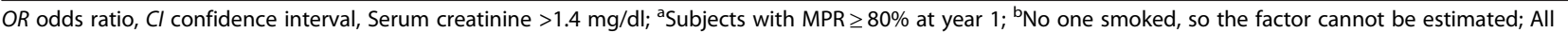
comparisons denote present vs. absent.

not analyzed annually, as done in our investigation. Data on several characteristics of male subjects, e.g., jobs, lifestyle, and educational levels, were not collected, which potentially may be related to compliance with therapy in the current study. Hence, our finding suggests that certain unidentified factors pertaining to male subjects may be related to poor compliance, as demonstrated by previous studies.

In our study, patients of orthopedists were more likely to discontinue osteoporosis medications at year 1 than those seeing rheumatologists. This is in agreement with a previous study showing that patients of orthopedists were more likely to discontinue their medications than the patients of rheumatologists and general practitioners, probably due to a lack of adequate doctor motivation [42]. Physician specialty was significantly associated with adherence to treatment guidelines [43]. Ideguchi et al. found that patients of gynecologists or rheumatologists were more likely to continue bisphosphonates than patients of orthopedists or other specialists [44]. BMD measurement was highest among patients treated with glucocorticoids prescribed by rheumatologists [45]; therefore, rheumatologists often had more opportunities to prescribe antiosteoporotic medications to prevent or treat GIOP than other specialties. We speculated from our study results that having follow-up for each long-term prescription by a physician specializing in osteoporosis (especially an internist, for example, a rheumatologist) with feedback to the patients may improve the patient-physician relationship and adherence.

A lack of DXA at baseline (before therapy) was another factor of 1-year poor compliance in our study. Similar observations were also reported in Pickney's [46] and Solomon's studies [29]. In contrast, Hansen et al. showed that non-adherence to oral anti-osteoporosis medications among men was associated with a lack of measurements of bone mass during alendronate therapy, but not before therapy [14]. It has been demonstrated 
that a correct understanding of BMD results would lead to higher treatment rates and better adherence to treatment [46]. Adherers who have undergone bone mass measurements at baseline might be more aware of their disease course and of the risks of subsequent or recurrent fractures than non-adherers.

Richards et al. observed that non-adherence to bisphosphonates was common in a cohort of RA patients who were veterans in the United States [47]. In contrast, RA patients in our study were more likely to continue osteoporosis medications. We would expect good compliance with osteoporosis medications in patients with RA because of the awareness of physicians and patients about the negative effects of glucocorticoids on bone. Most patients with RA may need to receive steroid treatment in clinical practice, which puts them at high risk for GIOP. Rossini et al. demonstrated positive associations between glucocorticoid and anti-inflammatory treatment and compliance with osteoporosis medications [42]. Although steroid users did not have a higher compliance rate in the current study, other determining factors associated with adherence among osteoporotic RA male patients could be further explored in the future.

There are several limitations in our study. (1) It is unknown if patients actually took the dispensed drug. We assumed that patients who obtain prescription refills do take their medications based on chart review. In addition, in Taiwan, patients can obtain 2 to 3 prescriptions each visit for a stable disease. We were unable to ascertain whether patients obtained refills at outside pharmacies. As a result, adherence may be overestimated. (2) We determined adherence based on the number of refills. Therefore, whether the drug was delivered correctly at the correct time of day or in appropriate doses is unknown. (3) Due to the retrospective study design, some information obtained from chart reviews may be not complete and the data collection may be subjective. (4) We did not collect data on the side effects of antiosteoporotic regimens from the chart reviews, which may actually have influenced adherence. (5) Our sample size was relatively small. Therefore, we may not have determined all factors associated with non-adherence among male patients. (6) Finally, patient characteristics linked to adherence from databases at a single medical center probably were not universally applicable to men treated by community-based practitioners.

However, our study has some advantages. (1) We reviewed medical charts to determine patient variables associated with adherence, information that is often not acquired in claims databases. (2) Most studies reported on the adherence mainly of postmenopausal women; we targeted men who are not normally enrolled or included in osteoporosis adherence studies exclusively. (3) We analyzed adherence over a period of 2 years and identified patient-specific factors of poor adherence on a year-by -year basis. This information can serve as a reminder to prescribers year by year to improve adherence.

\section{Conclusions}

Our study indicates that men with osteoporosis are not optimally treated in daily clinical practice in southern Taiwan. Starting prescriptions by orthopedists significantly contributed to non-compliance, and men with RA and baseline bone mass measurements were less likely to have poor compliance. Identifying risk factors associated with non-adherence may help healthcare professionals improve adherence.

\section{Abbreviations}

(MPR): Median medication possession ratio; (IQR): Interquartile range; (OR): Odds ratio; (Cl): Confidence interval; (BMD): Bone mineral density; (RA): Rheumatoid arthritis; (CGMHK): Chang-Gung Memorial Hospital, Kaohsiung; (ICD-9-CM): International Classification of Diseases, Ninth Edition, Clinical Modification; (NOF): National Osteoporosis Foundation; (ACR): American College of Rheumatology; (GIOP): Glucocorticoid-induced osteoporosis; (DXA): Dual energy X-ray absorptiometry; (PR): Persistence rate; (SD): Standard deviation.

\section{Competing interests}

The authors have indicated that they have no conflict of interest regarding the content of this report.

\section{Authors' contributions}

All authors made substantive intellectual contributions to this study to qualify as authors. CC and MK contributed to study design, acquisition of data, analysis of data, and interpretation of results. SY and TC contributed to study coordination. BYS contributed to statistical analysis. CC, MK, SY and TC contributed to manuscript preparation. All authors read and approved the final manuscript.

\section{Acknowledgements}

The authors would like to thank Dr. Tsong-Shing Yang, Dr. Wen-Chan Chiu, Dr. Chung-Yuan Hsu, and Miss Su-Wei Chen for technical assistance. This study was supported by grant CMRPG870592 from Chang Gung Memorial Hospital and Chang Gung University College of Medicine, Kaohsiung, Taiwan.

\section{Author details}

'Division of Rheumatology, Allergy and Immunology, E-DA Hospital, I-Shou University, 1 ,Yi-Da Road, Jiau-shu Tsuen, Yan-chau Shiang, Kaohsiung, Taiwan. ${ }^{2}$ Division of Endocrinology \& Metabolism, Department of Internal Medicine, Kaohsiung Chang Gung Memorial Hospital and Chang Gung University College of Medicine, Kaohsiung, Taiwan. ${ }^{3}$ Division of Rheumatology, Allergy and Immunology, Department of Internal Medicine, Kaohsiung Chang Gung Memorial Hospital and Chang Gung University College of Medicine, No 123, Ta-Pei Road, Niaosung, Kaohsiung 833, Taiwan.

Received: 29 March 2013 Accepted: 17 September 2013

Published: 23 September 2013

\section{References}

1. Cole ZA, Dennison EM, Cooper C: Osteoporosis epidemiology update. Curr Rheumatol Rep 2008, 10(2):92-96.

2. Johnell O, Kanis J, Gullberg G: Mortality, morbidity, and assessment of fracture risk in male osteoporosis. Calcif Tissue Int 2001, 69(4):182-184.

3. Cree MW, Juby AG, Carriere KC: Mortality and morbidity associated with osteoporosis drug treatment following hip fracture. Osteoporos Int 2003, 14(9):722-727.

4. Mnif H, Koubaa M, Zrig M, Trabelsi R, Abid A: Elderly patient's mortality and morbidity following trochanteric fracture. A prospective study of 100 cases. Orthop Traumatol Surg Res 2009, 95(7):505-510.

5. Watts NB: Osteoporosis in Men. Endocr Pract 2013, 11:1-16. 
6. Romagnoli E, Del Fiacco R, Russo S, Piemonte S, Fidanza F, Colapietro F, Diacinti D, Cipriani C, Minisola S: Secondary osteoporosis in men and women: clinical challenge of an unresolved issue. J Rheumato/ 2011 38(8):1671-1679.

7. Yang NP, Deng CY, Chou YJ, Chen PQ, Lin CH, Chou P, Chang HJ: Estimated prevalence of osteoporosis from a Nationwide Health Insurance database in Taiwan. Health Policy 2006, 75(3):329-337.

8. Pande I, Scott DL, O'Neill TW, Pritchard C, Woolf AD, Davis MJ: Quality of life, morbidity, and mortality after low trauma hip fracture in men. Ann Rheum Dis 2006, 65(1):87-92.

9. Center JR, Nguyen TV, Schneider D, Sambrook PN, Eisman JA: Mortality after all major types of osteoporotic fracture in men and women: an observational study. Lancet 1999, 353(9156):878-882.

10. Gennari L, Bilezikian JP: Osteoporosis in men. Endocrinol Metab Clin North Am 2007, 36(2):399-419.

11. Eichner SF, Lloyd KB, Timpe EM: Comparing therapies for postmenopausal osteoporosis prevention and treatment. Ann Pharmacother 2003, 37(5):711-724

12. Geusens PP, Roux CH, Reid DM, Lems WF, Adami S, Adachi JD, Sambrook PN, Saag KG, Lane NE, Hochberg MC: Drug Insight: choosing a drug treatment strategy for women with osteoporosis-an evidence-based clinical perspective. Nat Clin Pract Rheumatol 2008, 4(5):240-248.

13. Kothawala P, Badamgarav E, Ryu S, Miller RM, Halbert RJ: Systematic review and meta-analysis of real-world adherence to drug therapy for osteoporosis. Mayo Clin Proc 2007, 82(12):1493-1501.

14. Hansen KE, Swenson ED, Baltz B, Schuna AA, Jones AN, Elliott ME: Adherence to alendronate in male veterans. Osteoporos Int 2008, 19(3):349-356.

15. Cevikoi A, Umay E, Polat S, Ecerkale O, Cakci A: The relationship between bisphosphonate use and demographic characteristics of male osteoporosis patients. Clinics (Sao Paulo) 2011, 66(4):579-582.

16. Lekkerkerker F, Kanis JA, Alsayed N, Bouvenot G, Burlet N, Cahall D, Chines A, Delmas $P$, Dreiser RL, Ethgen D, et al: Adherence to treatment of osteoporosis: a need for study. Osteoporos Int 2007, 18(10):1311-1317.

17. Gold DT, Alexander IM, Ettinger MP: How can osteoporosis patients benefit more from their therapy? Adherence issues with bisphosphonate therapy. Ann Pharmacother 2006, 40(6):1143-1150.

18. Briesacher BA, Andrade SE, Fouayzi H, Chan KA: Comparison of drug adherence rates among patients with seven different medical conditions. Pharmacotherapy 2008, 28(4):437-443.

19. Ensrud KE, Barrett-Connor EL, Schwartz A, Santora AC, Bauer DC, Suryawanshi S, Feldstein A, Haskell WL, Hochberg MC, Torner JC, et al: Randomized trial of effect of alendronate continuation versus discontinuation in women with low BMD: results from the Fracture Intervention Trial long-term extension. J Bone Miner Res 2004, 19(8):1259-1269.

20. Black DM, Schwartz AV, Ensrud KE, Cauley JA, Levis S, Quandt SA, Satterfield S, Wallace RB, Bauer DC, Palermo L, et al: Effects of continuing or stopping alendronate after 5 years of treatment: the Fracture Intervention Trial Longterm Extension (FLEX): a randomized trial. JAMA 2006, 296(24):2927-2938.

21. Netelenbos JC, Geusens PP, Ypma G, Buijs SJ: Adherence and profile of nonpersistence in patients treated for osteoporosis-a large-scale, long-term retrospective study in The Netherlands. Osteoporos Int 2011, 22(5):1537-1546.

22. Cotté FE, Fardellone P, Mercier F, Gaudin AF, Roux C: Adherence to monthly and weekly oral bisphosphonates in women with osteoporosis. Osteoporos In 2010, 21(1):145-155

23. Dawson-Hughes B, Lindsay R, Khosla S, Melton L, Tosteson A, Favus M: Clinician's Guide to Prevention and Treatment of Osteoporosis. Washington DC: National Osteoporosis Foundation; 2008.

24. American College of Rheumatology Ad Hoc Committee on Glucocorticoid Induced Osteoporosis: Recommendations for the prevention and treatment of glucocorticoid-induced osteoporosis: 2001 update. Arthritis Rheum 2001, 44(7):1496-1503.

25. Cramer JA, Roy A, Burrell A, Fairchild CJ, Fuldeore MJ, Ollendorf DA, Wong PK: Medication compliance and persistence: terminology and definitions. Value Health 2008, 11(1):44-47.

26. Yu SF, Chou CL, Lai HM, Chen YC, Chiu CK, Kuo MC, Su YJ, Chen CJ, Cheng $\Pi$ T: Adherence to anti-osteoporotic regimens in a Southern Taiwanese population treated according to guidelines: a hospital-based study. Int J Rheum Dis 2012, 15(3):297-305.

27. Weycker D, Macarios D, Edelsberg J, Oster G: Compliance with drug therapy for postmenopausal osteoporosis. Osteoporos Int 2006 , 17(11):1645-1652.
28. Recker RR, Gallagher R, MacCosbe PE: Effect of dosing frequency on bisphosphonate medication adherence in a large longitudinal cohort of women. Mayo Clin Proc 2005, 80(7):856-861

29. Solomon DH, Avorn J, Katz JN, Finkelstein JS, Arnold M, Polinski JM, Brookhart MA: Compliance with osteoporosis medications. Arch Intern Med 2005, 165(20):2414-2419.

30. Lin TC, Yang CY, Yang YH, Lin SJ: Alendronate adherence and its impact on hip-fracture risk in patients with established osteoporosis in Taiwan. Clin Pharmacol Ther 2011, 90(1):109-116.

31. Landfeldt E, Strom O, Robbins S, Borgstrom F: Adherence to treatment of primary osteoporosis and its association to fractures-the Swedish Adherence Register Analysis (SARA). Osteoporos Int 2012, 23(2):433-443.

32. Downey TW, Foltz SH, Boccuzzi SJ, Omar MA, Kahler KH: Adherence and persistence associated with the pharmacologic treatment of osteoporosis in a managed care setting. South Med J 2006, 99(6):570-575.

33. Clowes JA, Peel NF, Eastell R: The impact of monitoring on adherence and persistence with antiresorptive treatment for postmenopausal osteoporosis: a randomized controlled trial. J Clin Endocrinol Metab 2004, 89(3):1117-1123

34. Yood RA, Emani S, Reed JI, Lewis BE, Charpentier M, Lydick E: Compliance with pharmacologic therapy for osteoporosis. Osteoporos Int 2003, 14(12):965-968.

35. Soong YK, Tsai KS, Huang HY, Yang RS, Chen JF, Wu PC, Huang KE: Risk of refracture associated with compliance and persistence with bisphosphonate therapy in Taiwan. Osteoporos Int 2013, 24(2):511-521.

36. McCombs JS, Thiebaud P, McLaughlin-Miley C, Shi J: Compliance with drug therapies for the treatment and prevention of osteoporosis. Maturitas 2004, 48(3):271-287.

37. Boonen S, Kay R, Cooper C, Haentjens P, Vanderschueren D, Callewaert F Milisen K, Ferrari S: Osteoporosis management: a perspective based on bisphosphonate data from randomised clinical trials and observational databases. Int J Clin Pract 2009, 63(12):1792-1804.

38. Lo JC, Pressman AR, Omar MA, Ettinger B: Persistence with weekly alendronate therapy among postmenopausal women. Osteoporos Int 2006, 17(6):922-928.

39. Gold DT, Silverman S: Review of adherence to medications for the treatment of osteoporosis. Curr Osteoporos Rep 2006, 4(1):21-27.

40. Carnevale V, Nieddu L, Romagnoli E, Bona E, Piemonte S, Scillitani A, Minisola S: Osteoporosis intervention in ambulatory patients with previous hip fracture: a multicentric, nationwide Italian survey. Osteoporos Int 2006, 17(3):478-483.

41. Devold HM, Furu K, Skurtveit S, Tverdal A, Falch JA, Sogaard AJ: Influence of socioeconomic factors on the adherence of alendronate treatment in incident users in Norway. Pharmacoepidemiol Drug Saf 2012, 21(3):297-304.

42. Rossini M, Bianchi G, Di Munno O, Giannini S, Minisola S, Sinigaglia L, Adami S: Determinants of adherence to osteoporosis treatment in clinical practice. Osteoporos Int 2006, 17(6):914-921.

43. Grossman Z, Silverman BG, Miron D: Physician specialty is associated with adherence to treatment guidelines for acute otitis media in children. Acta Paediatr 2013, 102(1):e29-33.

44. Ideguchi $\mathrm{H}$, Ohno S, Hattori $\mathrm{H}$, Ishigatsubo $\mathrm{Y}$ : Persistence with bisphosphonate therapy including treatment courses with multiple sequential bisphosphonates in the real world. Osteoporos Int 2007 18(10):1421-1427.

45. Curtis JR, Westfall AO, Allison JJ, Becker A, Casebeer L, Freeman A, Spettell CM, Weissman NW, Wilke S, Saag KG: Longitudinal patterns in the prevention of osteoporosis in glucocorticoid-treated patients. Arthritis Rheum 2005, 52(8):2485-2494.

46. Pickney CS, Arnason JA: Correlation between patient recall of bone densitometry results and subsequent treatment adherence. Osteoporos Int 2005, 16(9):1156-1160.

47. Richards JS, Cannon GW, Hayden CL, Amdur RL, Lazaro D, Mikuls TR, Reimold AM, Caplan L, Johnson DS, Schwab P, et al: Adherence with bisphosphonate therapy in us veterans with rheumatoid arthritis. Arthritis Care Res (Hoboken) 2012, 64(12):1864-1870.

doi:10.1186/1471-2474-14-276

Cite this article as: Chiu et al:: Adherence to osteoporosis regimens among men and analysis of risk factors of poor compliance: a 2-year analytical review. BMC Musculoskeletal Disorders 2013 14:276. 